\title{
PROCESSOS E POLÍTICAS DE AVALIAÇÃO NO CEARÁ: cooperação e responsabilização
}

\author{
Erineuda do Amaral Soares 1 \\ Flávia Obino Corrêa Werle²
}

\section{RESUMO}

O presente estudo tem como objetivo analisar os revérberos da avaliação da educação nas últimas décadas no Brasil. Explicita o uso de premiação e incentivos financeiros propostos pelos estados a partir dos resultados dos alunos nessas avaliações. O exemplo apresentado é o Prêmio Escola Nota Dez no Ceará. Foi usada a revisão bibliográfica como metodologia, priorizando o enfoque comparado dos principais documentos legais que embasam as avaliações em larga escala tanto na esfera internacional, como nacional e estadual. Conclui-se que os resultados das avaliações em larga escala dos estados brasileiros influenciam as políticas públicas educacionais, principalmente nos repasses financeiros às escolas e municípios com maior e menores índices obtidos nas avaliações. As avaliações, nesse contexto, seguem a lógica da educação contábil e replicação das experiências exitosas por meio de uma cooperação técnicopedagógica de transferência das práticas que deram 'certo' numa tentativa de qualificar, porém, também uniformizando o ensino.

Palavras-chave: Avaliação. Políticas Educacionais. Cooperação.

\section{PROCESSES AND EVALUATION POLICIES IN CEARÁ: cooperation and liability}

\begin{abstract}
This study aims to analyze the education evaluation results in the last decades in Brazil. It focuses on the use of awards and financial incentives proposed by the states based on the students' results. The methodology used was a literature review, prioritizing a comparison of the main legal documents that support the large-scale evaluations at the international, national and state levels. The conclusion is that the large-scale evaluation results put forth by Brazilian states influence educational public policies, mainly, in the transfer of funds to the schools of municipalities with higher and lower indices obtained in the evaluation process. Evaluations, in this context, follow the logic of accounting education and replication of successful experiences through a technical-pedagogical cooperation of transfer of practices that worked well in an attempt to qualify, while standardizing teaching.
\end{abstract}

Keywords: Evaluation. Educational Policies. Cooperation.

\footnotetext{
1 Mestra em gestão educacional - UNISINOS, coordenadora pedagógica da rede pública de ensino do município de Fortaleza. E-mail: soareserineuda@hotmail.com

2 Doutorado em Educação. Professora titular da Universidade do Vale do Rio dos Sinos, vinculada ao Programa de Pós-Graduação em Educação. E-mail: flaviaw2008@gmail.com
} 


\section{PROCESOS Y POLÍTICAS DE EVALUACIÓN EN CEARÁ: cooperación y responsabilidad}

\section{RESUMEN}

El presente estudio tiene el objetivo de analizar los reflejos de la evaluación de la educación en las últimas décadas en Brasil. Detalla el uso de premios e incentivos financieros ofrecidos por los estados a partir de los resultados de los estudiantes. El ejemplo presentado es el Premio Escuela Nota Diez en Ceará. Se utilizó una revisión bibliográfica como metodología, priorizando el enfoque comparado de los documentos legales que fundamentan las evaluaciones en larga escala en las esferas internacionales, nacionales y provinciales. Se concluye que los resultados de las evaluaciones en larga escala de los estados brasileños influyen en las políticas públicas educacionales, en particular, en las transferencias de recursos financieros a las escuelas y municipios con mayor y menores índices obtenidos en las evaluaciones. Las evaluaciones, en este contexto, siguen la lógica de la educación contable y la reproducción de las experiencias exitosas por medio de una cooperación técnico-pedagógica de la transferencia de las 'buenas' prácticas en un intento de calificar, pero también uniformando o la enseñanza.

Palabras clave: Evaluación. Políticas Educativas. Cooperación.

\section{INTRODUÇÃO}

O presente trabalho é resultado do aprofundamento de pesquisa oriunda da dissertação de mestrado e tem como objetivo principal analisar dois programas provenientes das Políticas de Cooperação na Educação no estado do Ceará que têm como pedra de toque os resultados da aprendizagem das crianças. Buscamos refletir sobre a ampliação dessas políticas e como os resultados da avaliação de larga escala são conduzidos por tais políticas, inclusive, com premiação, bonificação e incentivos financeiros.

Destarte, compreendemos que a abordagem das políticas de cooperação como fenômeno que motiva a avaliação de larga escala fazse relevante neste momento, principalmente, porque desvela e traz a compreensão do contexto em que estas se manifestam. Portanto, alvitrar uma discussão sobre essas políticas no âmbito educacional pressupõe refletir sobre os efeitos implícitos que elas produzem dentro das instituições escolares, bem como, observar os impactos e os desafios colocados às 
pessoas que constituem essas instituições. Logo, lança-se o olhar sob a avaliação e suas consequências para quem está na "ponta do sistema".

Para Marcondes (2005), a análise da educação, os regionalismos e especificidades locais devem ser levados em consideração, de modo que sua comparação possibilite encontrar semelhanças em diferentes sistemas educativos. Para a referida autora, "As transformações dos sistemas de ensino são percebidas com maior profundidade na medida em que se pesquisam não apenas os contextos educacionais nacionais, mas também os internacionais, para relacioná-los, compará-los e analisá-los" (MARCONDES, p.147, 2005). Nesse sentido, esperamos que este trabalho possa contribuir com os debates sobre as políticas de cooperação, bonificação e incentivos financeiros $e$ as mudanças que elas vêm produzindo nas políticas avaliativas e, consequentemente, nas escolas de todo o país.

O trabalho está organizado em seis sessões que se relacionam entre si. Apresentamos na primeira o objetivo e relevância do nosso objeto de estudo. Na segunda, discorremos sobre a fundamentação teórica. A seguir, discorre-se sobre a metodologia, seguida das análises, discussões sobre a premiação, incentivos financeiros a partir dos resultados das avaliações em larga escala e conclusão.

\section{DAS AVALIAÇÕES INTERNACIONAIS ÀS POLÍTICAS AVALIATIVAS NACIONAIS E ESTADUAIS}

As exigências de avaliação perante as escolas não surgem por acaso. Segundo Akkari (2011), tais exigências são consequências da busca de elevação dos padrões de ensino, ou seja, pela busca da qualidade. Conforme esse autor, as avaliações nacionais e internacionais emergem como uma das facetas da internacionalização das políticas educacionais.

Para Lessard e Carpentier (2016), a necessidade de mudar os sistemas de educação começou a partir dos anos de 1980, quando os países membros da Organização de Cooperação e de Desenvolvimento Econômico (OCDE) mostraram preocupação em oferecer um ensino de 
melhor qualidade, para, enfim, atenderem a demanda econômica e social cada vez mais complexa.

Os autores citam que diferentes relatórios internacionais dos anos de 1990 listam as finalidades educativas propostas pelas organizações internacionais, dentre eles, o documento Pronto para a Vida, que traz as competências que os jovens deveriam desenvolver para desempenhar um papel produtivo na contemporaneidade.

Nesse contexto, os países, em uma operacionalização de prestação de contas, estão cada vez mais empenhados em um movimento de reestruturação de seus sistemas educacionais em nome de maior eficiência e qualidade. Tal pensamento resultou em uma formatação do sistema de ensino que elabora planos de estudo indicando exatamente o que o aluno deve dominar, e estabelece procedimentos de avaliação para verificar se os alunos atingiram os padrões estabelecidos (AKKARI, 2011).

Segundo Lessard e Carpentier (2016), o florescimento das grandes enquetes internacionais quantitativas nos anos de 1990 exerceu impacto nas políticas educativas de diferentes países. Tal política tem como meta a busca de leis invariantes que, na maioria das vezes, buscam detectar práticas adequadas para generalizá-las. Nesse contexto, as avaliações internacionais serviram como elo entre as pesquisas e essas políticas que buscam regular e responsabilizar os agentes públicos.

Conforme Brooke (2006), dois pontos principais têm sustentado a necessidade de implementação das políticas de responsabilização nos sistemas educacionais. 1) A disputa entre nações ricas por um lugar competitivo no mercado. 2) Recursos destinados à educação e, consequentemente, a necessidade de aferir a eficácia desse investimento. Tais fatores têm levado à preocupação exacerbada com os resultados dos sistemas de educação e exigido maiores informações referentes aos resultados das escolas.

Dessa forma, segundo esse autor, em resposta a essa preocupação surge a implementação dessas políticas no âmbito educacional que além de tornarem públicas as informações sobre o trabalho das escolas, 
consideram os gestores e membros da equipe escolar como corresponsáveis pelo resultado alcançado nas avaliações de larga escala.

De acordo com Brooke (2006), Inglaterra e Estados Unidos são exemplos da implementação dessa nova política em um contexto que ambos acreditam na relação entre produtividade econômica e educação. No entanto, os dois países têm experiências distintas quanto à recepção dessa aferição da qualidade do ensino. Enquanto estes avançam na consolidação dessa política, naquele, incialmente, há reação negativa e perda de entusiasmo por parte da comunidade acadêmica e autoridades locais. Isso porque os primeiros ranqueamentos das escolas não consideravam as diferenças socioeconômicas, nem aprendizagem prévia das crianças avaliadas.

Sob a mesma lógica da relação entre produtividade econômica e educação, Lessard e Carpentier (2016) expõem que, no contexto em que surgem as políticas institucionais baseadas em resultados, muitas pressões foram exercidas nos sistemas escolares para que eles cumprissem as funções que a sociedade e a economia lhes conferiam, baseando essas políticas na eficácia e eficiência.

Desse modo, esses sistemas passaram de um regime burocráticoprofissional para novos modos de regulação baseados em resultados que combinam elementos de automatização, responsabilização dos estabelecimentos e concorrência. Nesse modelo de regulamentação há obrigação dos responsáveis de prestar contas não só no âmbito hierárquico, mas também, aos usuários e parceiros da instituição (LESSARD; CARPENTIER, 2016).

Ainda conforme Brooke (2006), há uma convicção e velocidade em se adotar a responsabilização nos sistemas públicos de ensino. A migração de tal política de um país para o outro, segundo o autor, dá-se pela difusão das agências internacionais e circulação da livre informação. Entretanto, há de se verificar se as condições e as motivações para a implementação dessa política nos estados brasileiros são as mesmas desses países. Isso porque, no 
que se refere aos recursos alocados ao setor educacional, observa-se, no Brasil, o inverso de outros países (BROOKE, 2006).

O fato é que essas políticas vêm sendo implementadas com veemência em diversos países. A partir dos anos 2000, vários países passam a discutir os resultados do Programa Internacional de Avaliação de Estudantes (PISA) e a reestruturar seus sistemas a partir dos resultados dessa avaliação.

No Brasil, o quadro geral de políticas públicas de educação aponta uma estrutura de avaliação implementada desde o final dos anos oitenta. Em 2005, com a primeira aplicação da Prova Brasil, ocorre uma consolidação no campo das Avaliações de Larga Escala (WERLE, 2011). É a partir desse momento que esse tipo de avaliação é valorizado nacionalmente, por receber importante legitimação a partir de ações vinculadas à classificação de instituições de ensino, à liberação de recursos, à valorização da 'transparência' para a sociedade e à necessidade de qualificação da educação (WERLE, 2010).

No que diz respeito às avaliações em larga escala no Brasil, Bonamino e Sousa (2012) afirmam que dentre os marcos presentes na formulação e implementação de políticas educacionais as avaliações incorporaram elementos comuns aos de outros países, seguindo uma agenda mundial. Desse modo, há, portanto, um movimento de utilização das avaliações para mensurar o desempenho escolar dos alunos sob os mesmos parâmetros curriculares, como na maioria dos países.

Consoante às análises das referidas autoras, os desenhos das avaliações supramencionadas permitem identificar três gerações de avaliações da educação que coexistem no âmbito das redes de ensino. Tais gerações influenciam o currículo escolar de forma diferenciada, visto que dependendo do uso dos resultados das avaliações pelo governo e sociedade implicará na responsabilização dos profissionais que atuam nos sistemas de ensino.

Cabe aqui destacar as classificações utilizadas pelas autoras como recurso analítico das três gerações de avaliações. A primeira geração apresenta caráter diagnóstico sem atribuição direta para as escolas e 
currículo. O objetivo é acompanhar a qualidade da educação com a divulgação para consulta pública na internet, sem que haja uma devolução dos resultados para escola (BONAMINO; SOUSA, 2012).

Já as avaliações de segunda e terceira geração possuem caráter subsidiário das políticas de responsabilização, com atribuição de consequências para agentes escolares de acordo com os resultados dos alunos avaliados. Na segunda geração, o objetivo é propiciar a apropriação dos resultados das escolas pelos pais e sociedade que pressionam a escola por melhoria na educação. Enquanto que a terceira, além dessa divulgação, contempla sanções ou recompensas em decorrência dos resultados obtidos por alunos e escolas.

De acordo com Bonamino e Sousa (2012), essas avaliações operam dentro de uma estrutura idealizada que associa gestão democrática da educação, avaliação e responsabilização. Nesse contexto, a avaliação de políticas e programas se destacam como meio de mensurar seu desempenho e prestar contas à sociedade.

No Ceará, não por acaso, em 2007 é institucionalizado o Programa Alfabetização na Idade Certa - PAIC e, consequentemente, o governo estadual cria mais uma avaliação em larga escala, que visa avaliar a aprendizagem de todas as crianças dos $2^{\circ}$ anos do Ensino Fundamental: o Sistema Permanente de Avaliação da Educação Básica do Ceará Alfabetização (SPAECE-Alfa) (SOARES; WERLE, 2016).

Nesse contexto, é relevante compreender a relação entre as influências dessa política de cooperação e as interfaces que implicam as avaliações de terceira geração, especialmente, no tocante ao incentivo financeiro que tem permeado essas políticas em nosso país. Principalmente porque houve assimilação dessas orientações que, a princípio, foram determinações nacionais que, implementadas no estado do Ceará como experiência exitosa e bem sucedida, corroboraram para a efetivação de políticas que hoje abrangem toda educação brasileira, caso do Programa Nacional de Alfabetização na ldade Certa (PNAIC) (RABELO, 2016). 
De acordo com o autor supracitado, tal experiência é um instrumento básico de valorização do Pacto Nacional, uma vez que amplia o esforço de avançar na alfabetização de crianças e na formação das competências alfabetizadoras dos nossos professores no ensino fundamental.

\section{Marco legal das Políticas de Cooperação}

Partimos do marco legal, após a redemocratização do país, ocorrida em 1985, para iniciar a fundamentação do Regime de Colaboração. A Constituição Federal (CF) de 1988 associou um dos padrões de organização mais descentralizados das federações com a ideia de um sistema nacional de ensino equânime, por meio da regulamentação do regime de colaboração (ARAÚJO, 2010). No entanto, não há uma prescrição mais clara nos documentos oficiais quanto à definição desse regime que poderia "equalizar as graves desigualdades regionais e intraestatais, estabelecendo uma cooperação vertical [...], significando um caminho aberto para o estabelecimento futuro de cooperações horizontais entre os entes federados" (ARAÚJO, 2010, p. 762).

Apesar dessa indefinição quanto ao papel da União no que diz respeito à cooperação técnica, amparado no Art. 211 da Constituição Federal de1988, o governo do Ceará criou o Programa Alfabetização na Idade Certa - PAIC de cooperação técnica e incentivo para melhoria dos indicadores de aprendizagem nos municípios cearenses. A Lei n 14.026 , de 17 de dezembro de 2007, explicita em seus artigos sua finalidade:

Art. $1^{\circ}$ Fica instituído o Programa Alfabetização na Idade Certa - PAIC, por meio do qual o estado, em cumprimento ao regime de colaboração, poderá prestar cooperação técnica e financeira aos municípios cearenses, com vistas à melhoria dos resultados de aprendizagem.

Art. $2^{\circ}$ O Programa Alfabetização na Idade Certa - PAIC tem por finalidade o estabelecimento de condições necessárias para que todos os alunos cearenses cheguem ao $5^{\circ}$ ano do Ensino Fundamental sem distorção de idade, série e com o domínio das competências de leitura, escrita e cálculo adequado a sua idade e ao seu nível de escolarização.

Parágrafo único. Para maior garantia do cumprimento de seus objetivos, o Programa deverá, inicialmente, garantir a aquisição, por todas as crianças de 7 (sete) anos, das competências de leitura e escrita esperadas nesta idade. 
O PAIC, de acordo com esse documento, é uma política de colaboração entre o estado do Ceará e seus 184 municípios. Foi criado em parceria técnica e financeira com o Fundo das Nações Unidas para a Infância (UNICEF) e instituições da sociedade civil, com apoio do governo federal, e tem como objetivo alfabetizar todos os alunos das redes públicas de ensino do estado até os 7 anos de idade (CEARÁ, 2011).

A partir de 2011, o programa foi expandido para os alunos da rede pública até $05^{\circ}$ ano do Ensino Fundamental. Essa iniciativa é denominada PAIC MAIS e tem o objetivo de continuar as ações desenvolvidas pelo PAIC para qualificar a educação no estado, uma vez que os resultados do $5^{\circ}$ ano no Sistema Permanente de Avaliação da Educação Básica do Ceará (ESPAECE), segundo informações contidas no site do governo, ainda são muito baixos. Somente $10 \%$ dos alunos estavam no nível adequado em Português, e em Matemática apenas $6,9 \%$ dos alunos encontravam-se no nível adequado.

Em 2015, o governo lançou o Mais Paic - Programa de Aprendizagem na Idade Certa, com o objetivo de ampliar o trabalho de cooperação também para os anos finais do EF $\left(6^{\circ}\right.$ ao $9^{\circ}$ ano) nas escolas públicas cearenses.

O Ensino Fundamental II, que inclui as crianças do $6^{\circ}$ ao $9^{\circ}$ ano, teve seu acompanhamento pelo SPAECE a partir de 2012. Naquele ano, o percentual de alunos no nível adequado em Língua Portuguesa era de 8,6\%, enquanto que em Matemática era de $3,9 \%$. O SPAECE vem sendo utilizado pelo governo estadual como termômetro para avaliar o PAIC e, consequentemente, a qualidade da educação no estado. De acordo com os dados divulgados pela SEDUC, cerca de 310 mil alunos do $2^{\circ}, 5^{\circ}$ e $9^{\circ}$ anos do EF de mais de 4.500 escolas públicas participaram do SPAECE em 2016.

O PAIC mantém um Comitê de Articulação com funções consultivas, composto por: Associação para o Desenvolvimento dos Municípios do Estado do Ceará (APDM-CE), Associação dos Municípios e Prefeitos do Estado do Ceará (APRECE), Fórum de Educação Infantil, Secretaria de Estado da Cultura do Ceará (SECULT), União dos Dirigentes Municipais de 
Educação do Ceará (UNDIME-CE), União Nacional dos Conselhos Municipais de Educação (UNCME) e UNICEF. Cada um com sua contribuição na análise sistêmica do problema do analfabetismo escolar (CEARÁ, 2011; GUSMÃO; RIBEIRO, 2011).

QUADRO 1 - Componentes do Comitê de Articulação do PAIC e sua contribuição

\begin{tabular}{|c|c|}
\hline $\begin{array}{l}\text { Componentes } \\
\text { do Comitê de } \\
\text { Articulação do } \\
\text { PAIC }\end{array}$ & Contribuição na análise do analfabetismo \\
\hline APDM-CE & $\begin{array}{l}\text { Contribui com sua experiência na gestão de programas de } \\
\text { formação de leitores. }\end{array}$ \\
\hline APRECE & $\begin{array}{l}\text { Colabora com a mobilização dos prefeitos para assumir a liderança } \\
\text { dos processos em seus municípios. }\end{array}$ \\
\hline $\begin{array}{l}\text { Fórum de } \\
\text { Educação } \\
\text { Infantil }\end{array}$ & $\begin{array}{l}\text { Reúne militantes da área e coopera com questões relativas ao } \\
\text { significado de uma Educação Infantil de qualidade. }\end{array}$ \\
\hline SECULT & Reforça o vínculo entre escrita, leitura e cultura. \\
\hline UNCME & $\begin{array}{l}\text { Contribui com a articulação com os Conselhos Municipais de } \\
\text { Educação. }\end{array}$ \\
\hline UNDIME & $\begin{array}{l}\text { Colabora com a articulação e mobilização dos secretários de } \\
\text { Educação. }\end{array}$ \\
\hline UNICEF & $\begin{array}{l}\text { Agrega sua visão focada nos direitos da infância. Tem uma } \\
\text { trajetória de trabalho junto aos municípios do estado, pelo } \\
\text { Programa Selo UNICEF Município Aprovado, entre outras ações. }\end{array}$ \\
\hline
\end{tabular}

Fonte: CEARÁ, 2012; FONSECA, 2013; GUSMÃO; RIBEIRO 2011.

Desde o início do PAIC, uma das principais ações desse programa é verificar a aprendizagem através de avaliações externas. A primeira fase do PAIC consistiu na realização de duas avaliações externas em leitura e escrita dos alunos do $2^{\circ}$ ano, de caráter censitário, e seus resultados culminaram em formulação de estratégias contra o analfabetismo no estado.

O programa elaborava uma prova, pré-testava os itens, consolidava a avaliação e formava os municípios, por meio de assessoria técnica, para fazerem a aplicação. A avaliação diagnóstica da aprendizagem dos alunos era considerada a primeira etapa para a formulação de estratégias e implantação de ações visando à alfabetização de cada criança da rede 
de ensino. Concluídas as avaliações, o programa passou a apoiar os municípios pedagogicamente (CEARÁ, 2012).

Em 2007, reconhecido como um programa com foco na gestão voltada à aprendizagem do aluno e da gestão escolar, o governo do Ceará transformou o referido programa em política pública (CEARÁ, 2012). Nessa perspectiva, de acordo com a Lei $n^{\circ}$ 14.026/2007, o PAIC foi estruturado em cinco eixos de trabalho: I - Educação Infantil; II - Gestão Pedagógica Alfabetização e Formação de Professores; III - Gestão da Educação Municipal; IV - Formação do Leitor e V - Avaliação Externa de Aprendizagem. Segundo Fonseca (2013), esses eixos são interdependentes, indissociáveis e simultâneos e podem ser assim sintetizados:

QUADRO 2 - Eixos do PAIC, objetivos e principais metas do programa

\begin{tabular}{|c|c|c|}
\hline Eixo & Objetivo & Principais Metas \\
\hline $\begin{array}{l}\text { Educação } \\
\text { Infantil }\end{array}$ & $\begin{array}{l}\text { Apoiar os municípios na } \\
\text { implementação de políticas municipais } \\
\text { para educação infantil com o } \\
\text { propósito de promover a } \\
\text { universalização da educação das } \\
\text { crianças de } 0 \text { a } 5 \text { anos nas creches e } \\
\text { pré-escolas, contribuindo para a } \\
\text { elaboração de propostas pedagógicas } \\
\text { e qualificação de seus professores. }\end{array}$ & $\begin{array}{l}\text { 1. Ampliar o atendimento } \\
\text { das crianças de } 0 \text { a } 3 \text { anos } \\
\text { de idade. } \\
\text { 2. Atender } 100 \% \text { das } \\
\text { crianças de } 4 \text { a } 5 \text { anos de } \\
\text { idade. }\end{array}$ \\
\hline $\begin{array}{l}\text { Gestão } \\
\text { Pedagógica- } \\
\text { Alfabetização } \\
\text { e Formação } \\
\text { de Professores }\end{array}$ & $\begin{array}{l}\text { Formar os professores alfabetizadores } \\
\text { multiplicadores do } 1^{\circ} \text { ano e o } \\
\text { acompanhamento da formação dos } \\
\text { professores alfabetizadores do } 2^{\circ} \text { ano, } \\
\text { executada pelas editoras contratadas, } \\
\text { garantindo a alfabetização das } \\
\text { crianças matriculadas na rede pública } \\
\text { de ensino até o } 2^{\circ} \text { ano do Ensino } \\
\text { Fundamental. }\end{array}$ & $\begin{array}{l}\text { 1. Alfabetizar } 100 \% \text { das } \\
\text { crianças até o final do } 2^{\circ} \\
\text { ano, com comprovação } \\
\text { por meio do SPAECE-Alfa. }\end{array}$ \\
\hline $\begin{array}{l}\text { Gestão } \\
\text { Municipal }\end{array}$ & $\begin{array}{l}\text { Promover o fortalecimento institucional } \\
\text { dos sistemas municipais de ensino, } \\
\text { envolvendo assessoria técnica para a } \\
\text { estruturação de modelo de gestão } \\
\text { focado na aprendizagem, realizando } \\
\text { formação gerencial das equipes } \\
\text { técnicas das Secretarias Municipais de } \\
\text { Educação. }\end{array}$ & $\begin{array}{l}\text { Elevar o Índice de } \\
\text { Desenvolvimento } \\
\text { Educação Básica (IDEB) } \\
\text { dos anos iniciais do E F } \\
\text { para 6,0; Atender a } 100 \% \\
\text { das crianças de } 6 \text { a } 14 \\
\text { anos de idade; Reduzir o } \\
\text { abandono e a evasão } \\
\text { escolar para } 0 \% \text { nos anos } \\
\text { iniciais e finais do E F; } \\
\text { Corrigir o fluxo escolar E } \\
\text { Definir política de } \\
\text { acompanhamento das }\end{array}$ \\
\hline
\end{tabular}




\begin{tabular}{|c|c|c|}
\hline & & $\begin{array}{lll}\text { escolas } & \text { da } & \text { rede } \\
\text { municipal. } & & \\
\end{array}$ \\
\hline $\begin{array}{l}\text { Formação do } \\
\text { Leitor }\end{array}$ & $\begin{array}{l}\text { Incentivar a leitura por meio de acervos } \\
\text { literários nas salas de aula e através da } \\
\text { implementação de cantinhos de leitura } \\
\text { em todas as salas de aula de } \\
\text { Educação Infantil e } 1^{\circ} \text { e } 2^{\circ} \text { anos do } \\
\text { Ensino Fundamental. }\end{array}$ & $\begin{array}{l}\text { 1. Implementar cantinhos } \\
\text { de leitura em } 100 \% \text { das } \\
\text { salas de aula do } 1^{\circ} \text { e } 2^{\circ} \\
\text { ano. }\end{array}$ \\
\hline $\begin{array}{l}\text { Avaliação } \\
\text { Externa }\end{array}$ & $\begin{array}{l}\text { Promover a autonomia dos municípios } \\
\text { para que possam conduzir suas } \\
\text { próprias avaliações, criando os sistemas } \\
\text { municipais de avaliação externa; e } \\
\text { diagnosticar a situação de } \\
\text { aprendizagem da leitura, da escrita e } \\
\text { compreensão textual dos alunos dos } \\
\text { anos iniciais das redes municipais. }\end{array}$ & $\begin{array}{l}\text { 1. Disseminação da } \\
\text { avaliação externa no } \\
\text { município como } \\
\text { ferramenta para definição } \\
\text { de políticas. }\end{array}$ \\
\hline
\end{tabular}

Fonte: Quadro elaborado a partir dos trabalhos: CEARÁ, 2012; FONSECA, 2013; GUSMÃO, RIBEIRO, 2011; RABELO, 2016.

No que se refere à avaliação educacional, o PAIC trouxe a implementação de duas avaliações: a Prova PAIC e o Sistema Permanente de Avaliação da Educação Básica do Ceará-Alfabetização (SPAECE-Alfa). A primeira tem o objetivo de proporcionar um diagnóstico da alfabetização dos alunos dos anos iniciais do Ensino Fundamental (EF) para subsidiar o planejamento das intervenções pedagógicas pelos municípios e escolas de todo o estado do Ceará.

Nessa avaliação, os resultados dos municípios não são utilizados para composição de classificações, nem há bonificação ou algo semelhante, pois o objetivo principal é intervir pedagogicamente na aprendizagem das crianças avaliadas. Assim, o município é incentivado a tomar iniciativas pedagógicas quanto aos seus resultados.

O eixo avaliação do PAIC ajusta-se ao conceito de "alargar e apertar", que segundo Ball (2002), nas reformas educacionais consiste em delegar responsabilidade de gestão e valorizar o espírito de iniciativa de resolver problemas, ao passo que são instituídas novas formas de vigilância imediata e automonitoração. Neste caso específico, referimo-nos à segunda avaliação externa desse eixo que impõe aos municípios sistemas de avaliação/apreciação, definição e metas/objetivos, bem como, comparações de rendimentos/produção. 
A segunda avaliação é uma das vertentes do SPAECE, sistema de avaliação institucionalizada no estado em 2000, conhecida como SPAECEAlfa. Essa é uma avaliação censitária que objetiva avaliar todas as crianças matriculadas no $2^{\circ}$ ano do EF em Língua Portuguesa.

Nessa avaliação, ao contrário das Provas PAIC, a Secretaria de Educação do Ceará licita uma instituição especializada em avaliação em larga escala e as provas são realizadas ao final do ano letivo, com o objetivo de avaliar as políticas públicas instituídas por esse programa referentes à alfabetização das crianças do estado cearense (CEARÁ, 2012). Os resultados dos municípios são utilizados para composição de classificações e divulgados publicamente; os municípios recebem seus dados em relatórios por município, escola, turma, aluno e consolidado geral do estado.

Não só isso, mas os resultados dessas avaliações refletem diretamente na receita dos municípios e nos recursos direcionados para escolas. Isso porque dois mecanismos financeiros são empregados pelo governo do estado a fim de estimular a priorização da alfabetização pelos municípios:

1) a alteração dos critérios de distribuição da cota-parte dos municípios no Imposto sobre Circulação de Mercadorias e Serviços (ICMS);

2) criação do Prêmio Escola Nota Dez, que concede bonificação às 150 escolas com os melhores resultados de alfabetização do estado e contempla com recursos financeiros as 150 escolas com os menores resultados.

O PAIC surge nesse contexto como experiência exitosa de política cooperação e inspira políticas educacionais para todo país, como, por exemplo, o Pacto Nacional pela Alfabetização na Idade Certa (PNAIC), instituído em 2012, que também é uma política de cooperação assumida pelo Governo Federal e os demais entes federativos. A seguir, são mostrados aspectos relevantes dessa política que associa o desenho do PAIC ao PNAIC. 
QUADRO 3 - Elementos de Operacionalização do PAIC e PNAIC

\begin{tabular}{|c|c|c|}
\hline $\begin{array}{c}\text { ELEMENTOS DA } \\
\text { OPERACIONALIZAÇÃO }\end{array}$ & PAIC & PNAIC \\
\hline Objetivo principal & $\begin{array}{l}\text { Alfabetizar todas as crianças } \\
\text { até os sete anos de idade. }\end{array}$ & $\begin{array}{l}\text { Alfabetizar todas as crianças até } \\
\text { os oito anos de idade. }\end{array}$ \\
\hline Eixos de trabalho & 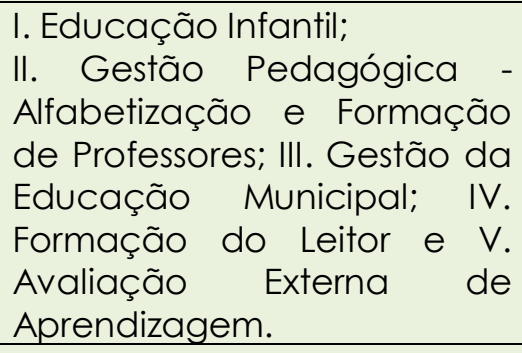 & $\begin{array}{l}\text { I.Formação continuada; } \\
\text { Il.Materiais didáticos; III. } \\
\text { Avaliações sistemáticas; IV. } \\
\text { Gestão, mobilização e controle } \\
\text { social. }\end{array}$ \\
\hline Avaliação & $\begin{array}{l}\text { Prova Paic e Avaliação } \\
\text { censitária para o final do } 2^{\circ} \\
\text { ano, SPAECE- Alfa. }\end{array}$ & $\begin{array}{l}\text { Avaliação censitária para o final } \\
\text { do } 3^{\circ} \text { ano, a Avaliação Nacional } \\
\text { da Alfabetização (ANA). }\end{array}$ \\
\hline Disciplinas avaliadas & Língua Portuguesa. & Língua Portuguesa e Matemática. \\
\hline
\end{tabular}

Fonte: Quadro elaborado a partir dos trabalhos de Gomes, 2013; Rabelo, 2016.

O PNAIC apresenta o objetivo de assegurar a alfabetização de todas as crianças, até os oito anos de idade, ao final do $3^{\circ}$ ano do E F. A exemplo do PAIC, O PNAIC também traz uma avaliação censitária para o final do $3^{\circ}$ ano, onde todos os alunos farão a Avaliação Nacional da Alfabetização (ANA). Também há diferença nas disciplinas avaliadas. Enquanto o SPAECEAlfa avalia apenas Língua Portuguesa, a ANA avalia, além dessa, a disciplina de Matemática.

O eixo da avaliação do PNAIC reúne três componentes principais: 1) avaliações processuais, que podem ser desenvolvidas e realizadas continuamente pelo professor; 2) Provinha Brasil de cada criança, no início e no final do $2^{\circ}$ ano, onde os docentes e gestores poderão acompanhar 0 desenvolvimento da aprendizagem de cada aluno; 3) ao final do $3^{\circ}$ ano, todos os alunos farão a avaliação supracitada que é coordenada pelo Instituto Nacional de Estudos e Pesquisas Educacionais (INEP).

Até o presente momento, a avaliação final ANA, talvez pela dimensão e sua abrangência, não se mostra tão consolidado no território brasileiro quanto o SPAECE-Alfa no estado do Ceará. A esse respeito, podemos citar a 
interrupção da aplicação da ANA no ano de 2015. Adiante, voltaremos a expor a implicação da política de colaboração no estado do Ceará.

\section{METODOLOGIA}

O estudo ora apresentado buscou trilhar os caminhos teóricos metodológicos comparativos. Seguimos os princípios implícitos que constituem as políticas públicas educacionais internacionais, buscando concatená-las às exigências das avaliações em larga escala por meio de estudo bibliográfico e análises de documentos legais que amparam a política de cooperação em nível local. Aproxima-se da metodologia utilizada na EC, uma vez que essa abordagem deve firmar-se no contexto educacional como um saber dinâmico e aberto metodologicamente (FERREIRA, 2008).

Dessa forma, o autor supracitado chama atenção não só para a necessidade da EC não se comprometer com apenas uma metodologia ou técnica específica, mas também para a importância de relacionar-se com outros domínios científicos. É sob essa perspectiva que encaminhamos este trabalho.

Sob essa ótica, no intuito de compreender o contexto onde são operacionalizadas as políticas avaliativas, buscamos verificar as aproximações existentes entre políticas educativas de cooperação no Brasil, abordando especificamente as implementadas no estado do Ceará que usam os resultados das avaliações em larga escala para repasses de verbas no intento de impulsionar o desempenho dos alunos pela premiação financeira.

Isso posto, expomos a premiação, bonificação e incentivos financeiros propostos por alguns estados brasileiros a seus municípios e escolas, numa tentativa de elevar seus índices de qualidade da educação. Vale ressaltar que no estado do Ceará esses índices são medidos, exclusiva e unicamente, pelas avaliações em larga escala, tendo maior peso o SPAECE. Ou seja, são os resultados dessa avaliação que são tomados, prioritariamente, como base para os repasses financeiros do estado aos seus municípios. 
Nessa perspectiva, através da EC será possível analisar a política de cooperação associada às políticas públicas educacionais, bem como, os incentivos financeiros repassados dos estados aos seus municípios, em particular, os do Ceará.

A análise dos dados se deu seguindo as seguintes etapas: primeiro a descrição da política de cooperação, coleta sistemática de informações nos livros, teses e documentos legais; interpretação, análise, comparação e discussão dessas políticas no contexto local.

Destarte, a seguir serão descritas as políticas públicas educacionais que tomam como referência a avaliação em larga escala para premiação e incentivos financeiros. Serão colocados em destaque o PAIC e o Programa Escola Nota Dez, bem como sua importância no contexto educacional local.

\section{RESULTADOS: apresentação e discussão}

A partir do levantamento bibliográfico, é possivel afirmar que um marco importante para o regime de colaboração do PAIC, segundo Gusmão e Ribeiro (2011), foi a normatização dos critérios de distribuição da cota-parte dos municípios no Imposto sobre Circulação de Mercadorias e Serviços (ICMS) que seguem critérios ligados às políticas públicas educacionais, incluindo os resultados das avaliações externas. Existem outros quatro estados que seguem caminhos similares. No entanto, a percentagem destinada à educação não chega a três por cento: Amapá, Pernambuco e Minas Gerais (BRANDÃO, 2014).

No Ceará, um quarto desse imposto (25\%), que corresponde à parcela transferida aos municípios (BRANDÃO, 2014), segue os resultados de três índices criados pelo governo cearense: o Índice de Qualidade da Educação (IQE), o Índice de Qualidade da Saúde (IQS), e o Índice de Qualidade do Meio Ambiente (IQM).

De acordo com a autora supracitada, até 2014, no que diz respeito aos critérios para rateio do ICMS nos estados brasileiros, sete estados seguem critérios tradicionais conforme a CF/88 e dezenove seguem critérios não 
tradicionais. Desses dezenove estados, quatro colocam critérios ligados à educação. Conforme exposto no quadro a seguir:

QUADRO 4 - Distribuição da cota- parte do ICMS nos estados brasileiros com critérios em Educação

\begin{tabular}{|l|l|}
\hline \multicolumn{1}{|c|}{ Estado Brasileiro } & Rateio do ICMS com critério em Educação \\
\hline Amapá & $2,6 \%$ \\
\hline Ceará & $18 \%(\mathrm{IQE})$ \\
\hline Minas Gerais & $2 \%$ \\
\hline Pernambuco & $2 \%$ \\
\hline
\end{tabular}

Fonte: Elaboração própria a partir do trabalho de Brandão, 2014.

Segundo Brandão (2014), o estado do Ceará é o único do país que adotou em sua legislação de distribuição de cota-parte do ICMS apenas critérios relacionados às políticas públicas. Foi, portanto, o estado que deu o maior peso a um critério ligado ao desempenho em políticas educacionais. No caso, $18 \%$ voltados para o indicador de resultado de "qualidade" na educação, até o presente momento. Outro detalhe diz respeito à fórmula do $I Q E$, que combina indicadores de Ensino Fundamental e alfabetização. O IQE corresponde a uma equação matemática que possibilita medir o nível e o avanço na qualidade do EF e da alfabetização das crianças cearenses, expresso no decreto $n^{\circ} 30.796$, de 29 de dezembro de 2011 .

QUADRO 5 - Distribuição da cota- parte do ICMS no Estado do Ceará com os critérios em Políticas Sociais

\begin{tabular}{|l|l|}
\hline \multicolumn{1}{|c|}{ Taxas do Repasse do ICMS } & \multicolumn{1}{|c|}{ Critérios de repasse do ICMS } \\
\hline $\begin{array}{l}75 \% \text { (três quartos), de acordo } \\
\text { com o Valor Adicionado Fiscal } \\
\text { (VAF). }\end{array}$ & \begin{tabular}{l} 
Depende do ICMS arrecadado por cada município. \\
\hline
\end{tabular} \\
$\begin{array}{l}\text { 25\% (um quarto), distribuídos } 18 \% \text { baseados no IQE distribuídos da seguinte forma: } \\
-12 \% \text { Baseados na avaliação dos alunos do segundo ano } \\
\text { entre os municípios com base } \\
\text { em critério sociais. }\end{array}$ & $\begin{array}{l}\text { número de alunos do } 2^{\circ} \text { ano do EF de nove anos da Rede } \\
\text { Municipal, matriculados e avaliados no SPAECE-Alfa; e a } \\
\text { universalização do aprendizado, calculado a partir dos } \\
\text { resultados do SPAECE-Alfa da seguinte maneira: Os } \\
\text { percentuais de alunos classificados como não } \\
\text { alfabetizados, com alfabetização incompleta e com } \\
\text { alfabetização desejável do município. }\end{array}$ \\
\hline
\end{tabular}




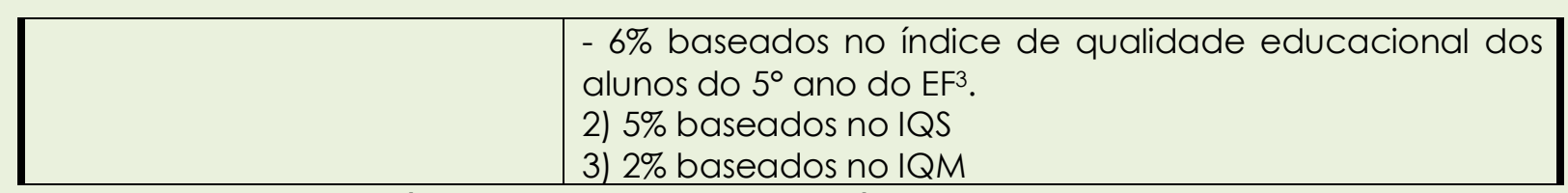

Fonte: Elaboração própria a partir de consulta à CARTILHA DO IPECE SOBRE ICMS, 2011; Gusmão, Ribeiro, 2011; Sales, Sequeira, 2011.

Segundo a cartilha de esclarecimento do IPECE (2011), a ordem da relevância das variáveis na cota-parte do ICMS é: primeiro, a Avaliação de Alfabetização (SPAECE-Alfa); segundo, as Avaliações Padronizadas (SPAECE e Prova Brasil); em terceiro, a taxa de aprovação no EF; em quarto lugar, a taxa de mortalidade infantil; e em quinto, os itens relativos ao meio ambiente.

Esse quadro explicita dois focos principais da gestão atual: o modelo de Gestão Pública por Resultados (GPR) adotada no Ceará e a supervalorização das avaliações em larga escala, usadas, principalmente, para verificar a qualidade do EF das escolas municipais. Portanto, trata-se de um modelo educacional amparado em ideias de educação contábil (LIMA, 2012) e de performatividade (BALL, 2002; ESQUINSANI, 2010).

Ball (2002), ao examinar as subjetividades da mudança e as subjetividades em mudança das atuais reformas educacionais, descreve os elementos-chave do 'pacote' da reforma de educação alastrada pelo mundo fundamentado no tripé: mercado, capacidade de gestão e performatividade.

Atualmente, a avaliação tem sido acionada como suporte de processos de prestação de contas e responsabilização, características de um Estado-avaliador (AFONSO, 2009) que tudo mensura. Nesse contexto, a performatividade é concebida como uma tecnologia, uma cultura e um modelo de regulação que serve de crítica, comparações como meio de controle e mudança. Os desempenhos individuais ou organizacionais servem para medir produtividade e rendimento (BALL, 2002).

Para esse autor, essas reformas trazem também uma nova linguagem no serviço público. Os recursos humanos necessitam de ser geridos e a

3 Critérios de distribuição até 2015, quando foram realizados os levantamentos dos dados para a pesquisa.

Revista Exitus, Santarém/PA, Vol. 8, № 2, p. 34 - 58, MAl/AGO 2018. 
aprendizagem é recompensada como um resultado de uma política de custo-efetivo (BALL, 2002).

A lógica da performatividade competitiva se origina não só de uma teoria econômica, mas, também, de práticas industriais que ligam organização e desempenho das escolas. Assim, envolve uma combinação de devolução do resultado do trabalho, metas e incentivos para replanejamento institucional (BALL, 2002).

\section{PRÊMIO ESCOLA NOTA DEZ: bonificação e contribuição financeira a partir dos resultados do SPAECE}

Seguindo essa lógica de devolução do resultado do trabalho das escolas e incentivos ao replanejamento institucional, outra política indutora para que as escolas melhorem seus resultados nos índices de desempenho escolar (IDE) do SPAECE é o Prêmio Escola Nota Dez, doravante chamado neste trabalho de PEND.

Vale ressaltar que o PEND também é vivenciado em outro estado brasileiro. Segundo Gomes (2011), no estado da Paraíba, no município de João Pessoa, esse prêmio é protagonizado pela Secretaria de Educação Municipal. Após sua regulamentação em 2009, é apresentado como mecanismo capaz de promover práticas escolares que visem a melhorias na qualidade do ensino público desse município.

No Ceará, com o objetivo de ampliar o trabalho empreendido pelo PAIC em relação à alfabetização de crianças e potencializar a capacidade de as escolas gerarem bons resultados nas avaliações externas, o governo do estado criou esse prêmio instituído pela Lei n 14.371, de 19 de junho de 2009.

O PEND é financiado pelo Fundo Estadual de Combate à Pobreza (FECOP) e administrado pela Secretaria de Educação do Estado do Ceará (SEDUC) (CEARÁ, 2015; CALDERÓN; RAQUEL; CABRAL, 2015). Segundo as autoras, se insere dentro da perspectiva das ações meritocráticas, a partir da mensuração do desempenho escolar, e trabalha com bonificação das 
escolas que alcançam os melhores resultados, por meio de incentivos financeiros. As escolas premiadas são estimuladas a apoiar outras que tenham apresentado baixos desempenhos através de ações de assistência e cooperação técnico-pedagógica (CALDERÓN; RAQUEL; CABRAL, 2015).

Incialmente, O PEND abrangeu apenas os alunos do segundo ano, associando a premiação, obrigatoriamente, aos resultados e participação dos alunos na avaliação SPAECE-Alfa. Atualmente, o referido Prêmio abrange também $\circ 5^{\circ}$ e $9^{\circ}$ anos. São premiadas até 150 escolas com melhores desempenhos e também são beneficiadas com contribuições financeiras, em igual número ao das escolas premiadas, as escolas públicas que obtiverem os menores resultados nas avaliações do SPAECE.

Destina-se às escolas públicas que obtêm melhor resultado de alfabetização, expresso por meio do Índice de Desempenho EscolarAlfabetização (IDE-Alfa), do Índice de Desempenho Escolar - $5^{\circ}$ ano (IDE-5) e do Índice de Desempenho Escolar - $9^{\circ}$ ano (IDE-9), apresentados nas avaliações SPAECE-Alfa e SPAECE, respectivamente (CEARÁ, 2015).

O prêmio, até o presente momento, corresponde à multiplicação do valor de $R \$ 2.000,00$ (dois mil reais) pelo número de alunos matriculados e avaliados no $2^{\circ}, 5^{\circ}$ e/ou $9^{\circ}$ anos. Dentre os critérios para premiação, estão: a média do IDE-Alfa situada no intervalo entre 8,5 (oito e meio) e 10,0 (dez); a média do IDE-5 e IDE-9 entre 7,5 (sete e meio) e 10,0 (dez) (CEARÁ, 2015).

No que diz respeito ao resultado do SPAECE-Alfa, especificamente, o PEND coloca como condição para receber o prêmio: a escola da Rede de Ensino do Município de Fortaleza deverá pertencer a um Distrito de Educação que tenha no mínimo $70 \%$ (setenta por cento) de alunos do $2^{\circ}$ ano do Ensino Fundamental de sua rede situados no nível "desejável" da escala de alfabetização. Isso, dentre outros efeitos, pressiona os gestores educacionais a buscarem, cada vez mais, bons resultados nessa avaliação.

Calderón, Raquel, Cabral (2015) afirmam que o PEND valoriza o mérito das escolas que atingiram as metas e induz relações de cooperação por meio da transferência de conhecimentos e experiências. Entretanto, não é possível verificar se isso se concretiza de fato, por não terem tempo hábil, 
uma vez que o prêmio vai apenas de um ano letivo ao outro. Assim, é possível verificar que, nessas instituições, a aquisição de materiais sobressai à aquisição de conhecimento, fato esse explicitado no referido trabalho.

Os pesquisadores, ao analisar 26 ações de cooperação técnicopedagógica implantadas por oito escolas premiadas e oito escolas apoiadas, constataram que todas foram implantadas com o objetivo de compartilhar experiências, transferindo conhecimentos e práticas pedagógicas que contribuíam para que as escolas obtivessem um bom desempenho no SPAECE.

Dentre essas ações, estão: a) Aulas de reforço escolar pautadas no nivelamento dos alunos em termos de aprendizagem; b) Uso de descritores e de simulados com familiarização dos alunos com as estruturas das avaliações externas e no alinhamento das avaliações externas com as avaliações internas na escola; c) Adoção de metodologias e práticas pedagógicas ativas em sala de aula na superação do ensino tradicional (CALDERÓN; RAQUEL; CABRAL, 2015).

A ênfase dada aos conteúdos abordados no SPAECE parece evidente nessas ações, a ponto de ser o "carro-chefe" das atividades desenvolvidas na escola, visto que seus resultados implicam arrecadação ou "punição" do município. Isso, dentre outros efeitos, tem levado às escolas a organizar os conteúdos a serem ministrados nos anos avaliados de acordo com o que é exigido nessa avaliação. Sobre essa priorização, Esteban (2008) chama atenção para o fato de que, na busca para elevação dos níveis de escolarização, dissociam-se os resultados escolares das redes socioculturais em que se tecem as diferentes dimensões da vida.

Essa dissociação leva à fragilidade de políticas públicas no campo educacional, ao isentar os conteúdos e práticas pedagógicas das marcas socioculturais dos sujeitos e seus contextos (ESTEBAN, 2008). Essas abordagens nem sempre resolvem os problemas escolares. Prova disso é que embora as relações de cooperação estimuladas pelo PEND tenham sido avaliadas na pesquisa como bem sucedidas por parte dos diretores das escolas pesquisadas, alguns problemas ainda persistem, tais como: evasão escolar; 
falta de hábito e interesse de dar continuidade nas atividades escolares em suas residências; falta de infraestrutura; distorção idade-série; excesso de alunos em sala de aula (CALDERÓN; RAQUEL; CABRAL, 2015).

Outra fragilidade desse tipo de política é que ao buscar premiar as escolas com melhores índices e ajudar financeiramente as com menores resultados, são colocadas à margem escolas que não estão nessas situações e que também precisam ser observadas. Cabe perguntar-se até que ponto essas escolas vêm desenvolvendo seu trabalho, uma vez que mesmo não sendo a melhor nem a 'pior', também estão inseridas no sistema educativo.

\section{CONSIDERAÇÕES FINAIS}

Este estudo teve como objetivo analisar os reflexos da avaliação da educação nas últimas décadas no Brasil buscando refletir sobre sua influência nas políticas públicas educacionais estaduais. Percebemos que 0 SPAECE-Alfa que surgiu em 2007, como uma das vertentes do SPAECE, para avaliar o Programa Alfabetização na Idade Certa - PAIC, uma política de cooperação técnica e incentivo à melhoria dos indicadores de aprendizagem nos municípios cearenses criada pelo governo estadual também em 2007, aos poucos vem sendo utilizado como pano de fundo para a formulação de políticas meritocráticas.

Duas estratégias são realizadas pelo estado do Ceará, que tomam como critérios os resultados e classificação na referida avaliação: o repasse da cota-parte ICMS e o Prêmio Escola Nota Dez. Essas estratégias, usadas pelo governo a partir dos resultados do SPAECE-Alfa, levam-nos a depreender que se fundamentam numa gestão de resultados, gerenciamento, e estão relacionadas à premiação, bonificação e repasse financeiro. Parece-nos um tanto contraditório e paradoxal quando um dos objetivos do SPAECE-Alfa é disponibilizar informações que possibilitem orientar as escolas quanto à construção da proposta pedagógica e da elaboração de seu planejamento.

Quanto às relações de cooperação estimuladas pelo PEND, cabe uma investigação das práticas desenvolvidas pelas escolas que não estão entre 
as melhores nem as 'piores' no ranking originado pelos resultados dessa avaliação. Seja qual for o motivo dessas instituições não estarem nessas posições, elas devem ser conhecidas pelos educadores e formuladores de política. Enfim, reforçamos a importância da reflexão e investigação como recurso, para educadores de todos os setores, para atuar de modo consciente em seu âmbito de trabalho.

\section{REFERÊNCIAS}

AFONSO, A. J. Nem tudo o que conta em educação é mensurável ou comparável. Crítica à accountability baseada em testes estandardizados e rankings escolares. Revista Lusófona de Educação, Lisboa, n 13, pp. 13-29, 2009.

AKKARI, A. Internacionalização das políticas educacionais: transformações e desafios. Petrópolis: Vozes, 2011.

ARAUJO, G. C. Constituição, Federação e propostas para o novo plano nacional de educação: análise das propostas de organização nacional da educação brasileira a partir do regime de colaboração. Educação \& Sociedade, Campinas, v. 31, n. 112, p. 749-768, jul-set. 2010.

BALL, S. Reformar Escolas/Reformar Professores $e$ os Terrores da Performatividade. Revista Portuguesa de Educação, Braga, Vol. 15, nº 2, pp. 3-23, 2002.

BONAMINO, A; SOUSA, S. Z. Três gerações de avaliação da educação básica no Brasil: interfaces com o currículo da/na escola. Educação e Pesquisa (USP. Impresso), v. 38, p. 373-388, 2012.

BRANDÃO, J. B. O rateio de ICMS por desempenho de municípios no Ceará e seu impacto em indicadores do sistema de avaliação da educação. 2014, Rio de Janeiro 2014. 87f. Dissertação (Mestrado em Administração) Fundação Getúlio Vargas - Rio de Janeiro, 2014.

BRASIL. Constituição (1988). Constituição da República Federativa do Brasil de $1988 . \quad$ Disponível em: <http://www.planalto.gov.br/ccivil_03/constituicao/constituicao.htm> Acesso em: 16 nov. 2016.

BROOKE, N. O Futuro das Políticas de Responsabilização Educacional no Brasil. Cadernos de Pesquisa, São Paulo, v. 36, n. 128, p 377-401, maio/ago. 2006.

CALDERÓN, A. I; RAQUEL, B. M. G; CABRAL, E. S. O Prêmio Escola nota 10: meritocracia e cooperação para a melhoria do desempenho escolar. Ensaio: Avaliação e Políticas Públicas em Educação, Rio de Janeiro, v. 23, n. 87, p. 517-540, abr./jun. 2015. 
CEARÁ. Instituto de Pesquisa Econômica do Ceará - IPECE. Cartilha da cota parte do ICMS. Fortaleza. 2009.

CEARÁ. Lei $n^{\circ}$ 14.026, de 17 de dezembro de 2007. Cria o programa alfabetização na idade certa - PAIC, de cooperação técnica e incentivo para melhoria dos indicadores de aprendizagem nos municípios cearenses e dá outras providências. Disponível em: <https://www.jusbrasil.com.br/diarios/5457768/pg-1-caderno-1-diario-oficialdo-estado-do-ceara-doece-de-19-12-2007 > Acesso em: 12 ago. 2016.

CEARÁ. Lei n $^{\circ} \mathbf{1 4 . 3 2 1}$, de 19 de junho de 2009. Cria o prêmio escola nota dez, destinado a premiar as escolas públicas com melhor resultado no índice de desempenho escolar alfabetização (IDE-alfa), e dá outras providências. Disponível em:<http://www.paic.seduc.ce.gov.br/index.php/o-paic/premioescola-nota-10> Acesso em: 16 ago. 2016.

CEARÁ. Lei $n^{\circ}$ 15.923, de 15 de dezembro de 2015. Institui o Prêmio Escola Nota Dez, destinado a premiar as escolas públicas com melhores resultados de aprendizagem no segundo, quinto e nonos anos do Ensino Fundamental. Disponível em:< https://www.jusbrasil.com.br/diarios/106463698/doececaderno-1-15-12-2015-pg-6> Acesso em: 14 abr. 2016.

CEARÁ. Secretaria da Educação. Regime de colaboração para a garantia do direito à aprendizagem: o Programa Alfabetização na Idade Certa (PAIC) no Ceará / Secretaria da Educação, Fundo das Nações Unidas para a Infância (UNICEF). Fortaleza: SEDUC, 2012.

ESQUINSANI, R.S.S. Performatividade e Educação: a política das avaliações em larga escala e a apropriação da mídia. Práxis Educativa, Ponta Grossa, v.5, n.2, p. 131-137, jul.-dez. 2010. Disponível em: < http://www.periodicos.vepg.br>. Acesso em: 16 fev. 2016.

ESTEBAN, M. T. Silenciar a polissemia e invisibilizar os sujeitos: Indagações ao discurso sobre a qualidade da educação. Revista Portuguesa de Educação, Braga, vol. 21, n 1, pp. 5-31, 2008.

FERREIRA, A. G. O sentido da Educação Comparada: Uma compreensão sobre a construção de uma identidade. Educação, Porto Alegre, v. 31, n. 2, p. 124-138, maio/ago. 2008.

FONSECA, A. S. A. Programa de Alfabetização na Idade Certa - PAIC: Reflexos no Planejamento e na Prática Escolar, 2013, 148 f. Tese (Doutorado) Universidade Federal do Ceará, Programa de Pós-Graduação em Educação Brasileira, Fortaleza, 2013.

GOMES, A. V. A. Alfabetização na Idade Certa: garantir a aprendizagem no início do Ensino Fundamental. Consultora Legislativa da Área XV Educação, Cultura, Desporto, Ciência e Tecnologia, Câmara do Deputados, 2013.

GOMES, I. F. Avaliação e qualidade de ensino: uma análise sobre o Prêmio Escola Nota Dez. 2011. 173 f. Dissertações (Mestrado em Educação) Universidade Federal da Paraíba, João Pessoa, 2011. 
GUSMÃO, J. B; RIBEIRO, V. M. Colaboração entre estado e municípios para a alfabetização de crianças na idade certa no Ceará. Cadernos Cenpec, São Paulo, v.1, n.1, p. 09-34, dez., 2011.

LESSARD, C; CARPENTIER, A. Políticas Educativas a aplicação na prática. Petrópolis: vozes, 2016.

LIMA, L. C. Elementos de análise organizacional das políticas e práticas de avaliação escolar. In: WERLE, F. (Org.). Avaliação em Larga Escala: questões polémicas. Brasília: Liber Livro Editora, 2012.

MARCONDES, M. A. S. Educação Comparada: perspectivas teóricas e investigações. ECCOS, São Paulo, v. 7, n. 1, p. 139-163, jun. 2005.

RABELO. C. D. PAIC e PNAIC no Ceará: por uma política de alfabetização e de formação de alfabetizadores sólida nos estados e municípios. Anais Simpósio Nacional de Política e Administração da Educação, 2016, v. 38, 2016.

SALES, J; SEQUEIRA, T. A (des)centralização fiscal e a gestão pública no Brasil: o perfil da repartição das quotas do ICMS no Pará, Minas Gerais e Ceará. In: Tópicos Avançados de Gestão, 5-32, Vila Real: CETRAD, 2011.

SOARES, E. A; WERLE, F. O. C. Sistema de avaliação da Educação Básica do Ceará: a importância do foco na aprendizagem. Revista Exitus, v. 6. n. 2, Julho/Dezembro de 2016.

WERLE, F. O. C. Sistema de avaliação da educação básica no Brasil: abordagem por níveis de segmentação. In: WERLE, F. O.C. (Org.). Avaliação em Larga Escala: foco na escola. São Leopoldo: OIKOS; Brasília: Liber Livro, 2010.

WERLE, F. O. C. Políticas de avaliação em larga escala na educação básica: do controle de resultados à intervenção nos processos de operacionalização do ensino. Ensaio: Avaliação e Políticas Públicas em Educação, Rio de Janeiro, v. 19, n. 73, p. 769-792, out./dez, 2011.

Recebido em: Agosto de 2017 Aprovado em: Fevereiro de 2018 